\title{
Sistemas Agroflorestais como Estratégia de Adaptação aos Desafios das Mudanças Climáticas no Brasil ${ }^{1,2}$
}

\author{
Altamir Schembergue ${ }^{3}$, Dênis Antônio da Cunha ${ }^{4}$, \\ Sabrina de Matos Carlos ${ }^{5}$, Marcel Viana Pires $^{6}$ e Raiza Moniz Faria ${ }^{7}$
}

Resumo: O presente artigo analisou o papel desempenhado pelos sistemas agroflorestais (SAF's) como medida adaptativa às mudanças climáticas no Brasil. Foi desenvolvido um modelo de efeito de tratamento (Propensity Score Matching), que permitiu identificar os principais determinantes do uso de SAF's e se municípios nos quais essa técnica é utilizada são menos vulneráveis às mudanças climáticas. Os resultados indicaram que variáveis socioeconômicas (propriedade da terra, opções de financiamento, acesso a informações e assistência técnica) e agronômicas (disponibilidade de recursos hídricos e qualidade do solo) influenciam a adoção de SAF's nos municípios brasileiros. As condições climáticas (temperatura e precipitação) também têm participação importante no emprego desses sistemas, o que confirma seu papel de estratégia adaptativa. Concluise também que os SAF's têm potencial de melhorar o desempenho agrícola brasileiro, já que o valor da terra tende a ser maior em municípios onde esses sistemas são utilizados. Desse modo, os SAF's podem tornar o setor agropecuário menos exposto aos efeitos negativos das mudanças climáticas, tanto no presente quanto em cenários futuros.

Palavras-chave: Mudanças climáticas; Agricultura; Adaptação; Sistemas agroflorestais.

DOI - http://dx.doi.org/10.1590/1234-56781806-94790550101

1. Data de submissão: 13 de julho de 2015. Data de aceite: 17 de agosto de 2016 .

2. Esta pesquisa foi apoiada pela Fundação de Amparo à Pesquisa do Estado de Minas Gerais (Fapemig), Conselho Nacional de Desenvolvimento Científico e Tecnológico (CNPq) e Coordenação de Aperfeiçoamento de Pessoal de Nível Superior (Capes/PNPD).

3. Universidade Estadual de Ponta Grossa (UEPG), Ponta Grossa, Paraná, Brasil. E-mail: aschembergue@gmail.com

4. Universidade Federal de Viçosa (UFV). Viçosa, Minas Gerais, Brasil. E-mail: denis.cunha@ufv.br

5. Universidade Federal de Viçosa (UFV). Viçosa, Minas Gerais, Brasil. E-mail: sabrinamcarlos@gmail.com

6. Universidade Federal de Viçosa (UFV). Viçosa, Minas Gerais, Brasil. E-mail: marcelpires@gmail.com

7. Universidade Federal de Viçosa (UFV). Viçosa, Minas Gerais, Brasil. E-mail: raizamoniz@gmail.com 
Abstract: This paper analyzes the role of agroforestry systems (AFS) as an adaptative measure to climate change in Brazil. A treatment-effects model (Propensity Score Matching) was developed. We identified the main determinants of the use of AFS and if the municipalities in which this technique is used are less vulnerable to climate change. The results showed that socioeconomic variables (land ownership, financing options, access to information and technical assistance) and agronomic variables (water resources availability and soil quality) influence the adoption of agroforestry systems in Brazilian municipalities. Climate conditions (temperature and precipitation) also play an important role in the use of these systems, which confirms their role as an adaptative strategy. It was also concluded that the AFS have the potential to improve the Brazilian agricultural performance due to the fact that the land value tends to be higher in municipalities where these systems are used. Thus, the AFS can make the agricultural sector less exposed to the negative effects of climate change in both the present and in future scenarios.

Key-words: Climate change, agriculture, adaptation, agroforestry systems.

Classificação JEL: Q12, Q54.

\section{Introdução}

Questões relacionadas à segurança alimentar e às mudanças climáticas têm sido cada vez mais debatidas, pois representam importantes desafios para a população mundial e envolvem diretamente o setor agrícola (KASTNER et al., 2012; NELSON et al., 2014). Segundo o Intergovernmental Panel on Climate Change (IPCC, 2014), os efeitos negativos das mudanças climáticas sobre a produção agropecuária já estão sendo observados em diferentes regiões do planeta, sobretudo nos países em desenvolvimento. A redução da produtividade de algumas culturas agrícolas é preocupante, uma vez que a demanda por alimentos poderá aumentar até $2 \%$ ao ano nas próximas décadas, devido à expectativa de crescimento populacional e melhoria nas condições econômicas de diversos países.

Ao mesmo tempo, é importante enfatizar que o setor agrícola também desempenha papel adverso nesse processo, uma vez que contribui para intensificar a mudança climática quando gases causadores de efeito estufa (GEE's) são liberados pelo desmatamento, uso de fertilizantes, pecuária e outras práticas agrícolas (BEDDINGTON et al., 2012). Atualmente, o setor de Agricultura, Florestas e Outros Usos da Terra (AFOLU - Agriculture, Forestry and Other Land Use Sector) é responsável por cerca de $30 \%$ de todas as emissões antropogênicas de GEE's. Apenas a produção agropecuária responde por metade do metano $\left(\mathrm{CH}_{4}\right)$ e dois terços do óxido nitroso $\left(\mathrm{N}_{2} \mathrm{O}\right)$ emitido como resultado de atividades humanas (IPCC, 2013).

O duplo papel desempenhado pelo setor agropecuário nas questões relacionadas às mudanças climáticas tem induzido o processo de intensificação sustentável da produção agrícola. De acordo com Ringler et al. (2014), ao aumentar a produção agrícola de forma sustentável, pode-se impactar positivamente a oferta de alimentos usando menos recursos e minimizando os impactos ambientais negativos. Dessa forma, é possível combinar práticas de adaptação, para aumentar a resiliência da agricultura, e de mitigação, visando reduzir as emissões de GEE's. Segundo Mbow et al. (2014a), explorar sinergias entre adaptação e mitigação é fundamental no setor AFOLU, sobretudo em países em desenvolvimento.

A combinação de maior produtividade e diminuição das pressões ambientais da agricultura pode ser alcançada de diferentes maneiras (KOOHAFKAN et al., 2012). Porém, poucas são as opções em que ganhos de produtividade são associados à maior diversidade agrossistêmica, como nos Sistemas Agroflorestais - SAF's (MBOW et al., 2014a). As práticas agroflorestais podem retardar ou reverter a degradação do solo, aumentar sua fertilidade, sequestrar carbono e garantir 
subsistência por meio do fornecimento de benefícios ecológicos e econômicos. Os SAF's, ao integrarem diferentes sistemas produtivos, como os de grãos, fibras, carne, leite e agroenergia, permitem a diversificação das atividades econômicas na propriedade, aumentando a lucratividade por unidade de área e minimizando os riscos de perdas de renda por eventos climáticos ou mesmo por condições adversas de mercado. Essas características explicam sua importância não só em termos de sustentabilidade agrícola, mas também nas questões relacionadas às mudanças climáticas (MBOW et al., 2014b).

De acordo com dados do Instituto Brasileiro de Geografia e Estatística (IBGE, 2006), existem cerca de 8,3 milhões de hectares de terras cultivadas com espécies florestais também usadas para lavouras e pastoreio no Brasil. Ademais, o Plano Setorial de Mitigação e de Adaptação às Mudanças Climáticas para a Consolidação de uma Economia de Baixa Emissão de Carbono na Agricultura (Plano $A B C$ ) vem incentivando o aumento da utilização de SAF's. O Plano ABC é uma das estratégias setoriais que compõem a Política Nacional sobre Mudanças do Clima PNMC (Lei no 12.187/2009). A PNMC visa reduzir as emissões de GEE's na economia brasileira. O Plano ABC, por sua vez, prevê a expansão da área utilizada com SAF's em quatro milhões de hectares até 2020 (BRASIL, 2013). Entretanto, mesmo diante das potencialidades desse tipo de sistema, tanto em termos de potencial de conservação de recursos naturais quanto de aumento de produtividade e geração de renda, a adoção de SAF's ainda é muito incipiente no Brasil. De acordo com o relatório "Propostas para a revisão do Plano ABC" (OBSERVATÓRIO ABC, 2015), a falta de conhecimento da prática de SAF's e a burocracia para obtenção de crédito (o Plano ABC tem exigências diferenciadas em relação ao crédito tradicional) são fatores que têm dificultado a adoção do sistema.

Nesse contexto, o presente estudo procurou contribuir para a literatura sobre a adoção de SAF's no Brasil, dando ênfase ao seu potencial de medida adaptativa às mudanças climáticas. $\mathrm{O}$ artigo procurou responder a duas questões: (i) quais são os principais condicionantes (socioeconômicos, agronômicos e climáticos) da adoção de SAF's no Brasil? (ii) municípios nos quais os SAF's foram implementados são menos vulneráveis às mudanças climáticas, em termos dos resultados econômicos da atividade agrícola, no presente e em cenários futuros?

Embora a literatura que trata da adoção de estratégias de adaptação às mudanças climáticas no Brasil esteja em expansão (MAY e VINHA, 2012; PIRES e CUNHA, 2014; FERREIRA FILHO e MORAES, 2015; CUNHA et al., 2015), as questões relacionadas à importância dos SAF's não têm sido exploradas nacionalmente. Assim, ao oferecer respostas mais concretas sobre a adoção de SAF's e suas potencialidades em termos de adaptação, pode-se gerar subsídios para que formuladores de política identifiquem vulnerabilidades e desenvolvam planos de ação capazes de minimizar as perdas esperadas resultantes das mudanças climáticas e também incentivar sua expansão no País.

\section{Sistemas agroflorestais e sua utilização no Brasil}

A compreensão dos principais condicionantes da adoção de SAF's e de seu papel como medida adaptativa às mudanças climáticas, temas deste artigo, deve passar, necessariamente, pelo entendimento de suas características e aspectos técnicos. Nesse sentido, a primeira parte dessa seção contextualiza os SAF's, indicando seu alcance e os requisitos mais importantes para o seu desenvolvimento. Na segunda parte é feito um panorama do uso de SAF's no Brasil.

\subsection{Definição de $S A F^{\prime}$ s e condicionantes de sua adoção}

De acordo com a definição mais aceita na literatura, proposta pelo International Centre for Research in Agroforestry, SAF's podem ser definidos como 
"[...] a collective name for land-use systems and technologies where woody perennials (trees, shrubs, palms, bamboos etc.) are deliberately used on the same land-management units as agricultural crops and/or animals, in some form of spatial arrangement or temporal sequence. In agroforestry systems there are both ecological and economical interactions between the different components" (LUNDGREN e RAINTREE, 1982).

A partir dessa definição, pode-se inferir que os SAF's representam atividades integradoras, que otimizam o uso da terra e apresentam potencialidades tanto no sentido ecológico quanto econômico, ou seja, permitem sustentabilidade ambiental e socioeconômica.

Em termos ecológicos, verifica-se que o uso de espécies arbóreas nos SAF's permite a recuperação de áreas degradadas, por meio da redução da erosão e aumento do acúmulo de matéria orgânica. Essa é uma importante diferença em relação à monocultura, na qual a perda da fertilidade do solo ocorre mais rapidamente. Ao mesmo tempo, é possível a restauração de florestas e até mesmo a redução do desmatamento. O plantio de espécies arbóreas de crescimento rápido nas fases iniciais possibilita o aumento da disponibilidade de biomassa, promovendo a ciclagem de nutrientes e, posteriormente, o cultivo de espécies mais exigentes. Ademais, com a prática de SAF's a disponibilidade de nutrientes no solo aumenta, a atividade e estrutura da fauna do solo melhoram e o equilíbrio biológico resultante auxilia no controle de pragas e doenças (EMBRAPA AGROBIOLOGIA, 2004).

Além dos aspectos conservacionistas de longo prazo e do aumento da diversidade agros-

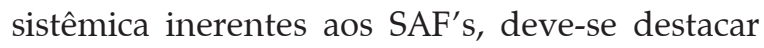
que, em termos econômicos, a possibilidade de geração de diferentes tipos de produtos garante maior produtividade e eficiência do trabalho, mais estabilidade da renda dos agricultores em curto e longo prazo, além de efeito positivo sobre a segurança alimentar. Tais ganhos são resultantes da possibilidade de estabelecer, na mesma área, consórcios entre frutas, hortaliças e outros produtos agrícolas, florestais e pecuários e também da menor necessidade de insumos externos, como fertilizantes sintéticos. Essas características permitem que os produtores rurais tenham maior habilidade para lidar com os impactos adversos que a agricultura vem sofrendo em função das mudanças climáticas globais. Portanto, é possível que aos agricultores antecipem-se a esses eventos, minorando os efeitos negativos que podem ser sentidos em sua produção e propriedade (MORAES et al., 2011; MEIJER et al., 2015a).

Existem diferentes maneiras de produzir utilizando SAF's, que vão desde a tradicional agricultura de rodízio que envolve o pousio florestal (MORAES et al., 2011) até arranjos comercias, como o sistema de integração lavoura-pecuária-floresta (iLPF). Como algumas dessas formas de SAF's requerem poucos insumos externos, pode-se afirmar que, em termos de necessidade de capital, sua utilização é adequada para qualquer tipo de produtor rural (MBOW et al., 2014b). Não obstante, a literatura especializada destaca que os fatores condicionantes da adoção de SAF's podem ser organizados em cinco categorias, quais sejam: preferências, disponibilidade de recursos, incentivos de mercado e institucionais, fatores biofísicos e risco/incertezas (PATTANAYAK et al., 2003; GONÇALVES e VIVAN, 2012; MEIJER et al., 2015a, 2015b).

Segundo Meijer et al. (2015b), as preferências refletem a ampla gama de características sociodemográficas específicas dos agricultores, que podem ser representadas por idade, sexo, educação, status social e fatores psicológicos, como atitudes pró-ambientais. A disponibilidade de recursos e os incentivos de mercado estão relacionados, respectivamente, à posse de bens, tais como terra e capital, e condições gerais de transporte e preços de produtos e insumos (PATTANAYAK et al., 2003). Mercados de crédito bem desenvolvidos e de amplo acesso, até mesmo para pequenos produtores, também têm papel essencial. Gonçalves e Vivan (2012) ressaltam ainda a importância de serviços públicos de extensão rural e assistência técnica, sindicatos e associações de produtores. No que se refere aos fatores biofísicos, pode-se afirmar que solos pouco férteis ou com propensão 
para erosão criam incentivos positivos à prática de SAF's, já que eles têm a capacidade de reverter tais características (GARRITY, 2004). Por fim, o fato de os SAF's possibilitarem a obtenção de diferentes produtos reduz riscos e incertezas inerentes às atividades agrícolas, sobretudo aquelas associadas às mudanças climáticas (MBOW et al., 2014a, 2014b).

No Brasil, além dos condicionantes citados acima, Gonçalves e Vivan (2012) destacam que o crescimento da prática de SAF's guarda relação direta com ações públicas voltadas para o desenvolvimento rural, redução de pobreza rural e conservação ambiental. Segundo os autores, algumas políticas governamentais, embora não diretamente voltadas para os SAF's, estimulam seu crescimento. Esse é o caso, por exemplo, do Programa de Aquisição de Alimentos (PAA) e do Programa Nacional de Alimentação Escolar (PNAE). Ao adquirem alimentos de origem agrícola, pecuária ou extrativa (no caso do PAA), esses programas estimulam mercados locais para os produtos originários dos SAF's. Há ainda políticas com estímulo direto aos SAF's, como é o caso do Programa Nacional de Fortalecimento da Agricultura Familiar (Pronaf), mais voltado ao desenvolvimento rural, e do Plano ABC, que busca reduzir emissões de gases de efeito estufa provenientes da agricultura.

A literatura que trata da adoção de SAF's no Brasil destaca diversos condicionantes socioeconômicos e institucionais que são decisivos para a adoção do sistema. Dos Santos et al. (2014), num estudo de caso para a cidade de Santa Maria do Pará (Amazônia Oriental), concluíram que o acesso à assistência técnica, nível de educação formal, experiência do agricultor com atividades agrícolas, participação em entidades de classe e título de propriedade da terra são importantes para a prática de SAF's. Pompeu et al. (2012), ao estudarem pequenos agricultores da região amazônica, confirmaram o papel decisivo da educação e também da disponibilidade e acesso ao crédito. O estudo de McGinty et al. (2008), que buscava analisar as dimensões sociais responsáveis pelo desenvolvimento ou manutenção de
SAF's em regiões de Mata Atlântica, concluiu que atitudes conservacionistas e a disponibilidade de mão de obra são essenciais.

\subsection{Panorama da utilização de $S A F^{\prime}$ 's no Brasil}

Os SAF's têm sido praticados com mais intensidade no Brasil desde a década de 1980, sobretudo por pequenos agricultores. Atualmente, o País conta com ampla variedade de sistemas, desde os quintais agroflorestais familiares, característicos das regiões de Mata Atlântica, até grandes consórcios comerciais, como a produção de café sombreada (GONÇALVES e VIVAN, 2012). De acordo com dados do Censo Agropecuário 2006 (IBGE, 2006), o Brasil possui aproximadamente 306 mil estabelecimentos agropecuários com uso de SAF's que, juntos, ocupam 8,3 milhões de hectares. ${ }^{8}$ Pouco mais da metade dessas propriedades encontra-se na região Nordeste (55\%).

A distribuição espacial da área utilizada com SAF's nos municípios brasileiros e do número de estabelecimentos adotantes do sistema são apresentados na Figura 1. Pode-se verificar que as áreas com maior expressividade estão localizadas na região Nordeste, o que, do ponto de vista agronômico, possivelmente é explicado pelas potencialidades do sistema em termos de manutenção de água e regeneração de fertilidade do solo, essenciais nos agroecossistemas da região Semiárida brasileira. Essa evidência está em conformidade com a proposição de que fatores biofísicos são importantes para a prática de SAF's (PATTANAYAK et al., 2003). Os estados do Pará e Acre e, com menos intensidade, Minas Gerais e Mato Grosso, também concentram muitos municípios com grandes áreas cultivadas com SAF's. Em termos do número de estabelecimentos, os municípios da região Sul também se destacam. A maior parte das regiões de fronteira agrícola do Centro-Oeste ainda tem baixa adesão a esse tipo de sistema de produção.

8. O IBGE apresenta, no Censo Agropecuário 2006, uma definição bem abrangente de sistemas agroflorestais: "área cultivada com espécies florestais, também usada para lavouras e pastoreio de animais". 
Figura 1. Distribuição espacial da área (ha) utilizada com SAF's

(a) e do número de estabelecimentos adotantes do sistema (b) nos municípios brasileiros
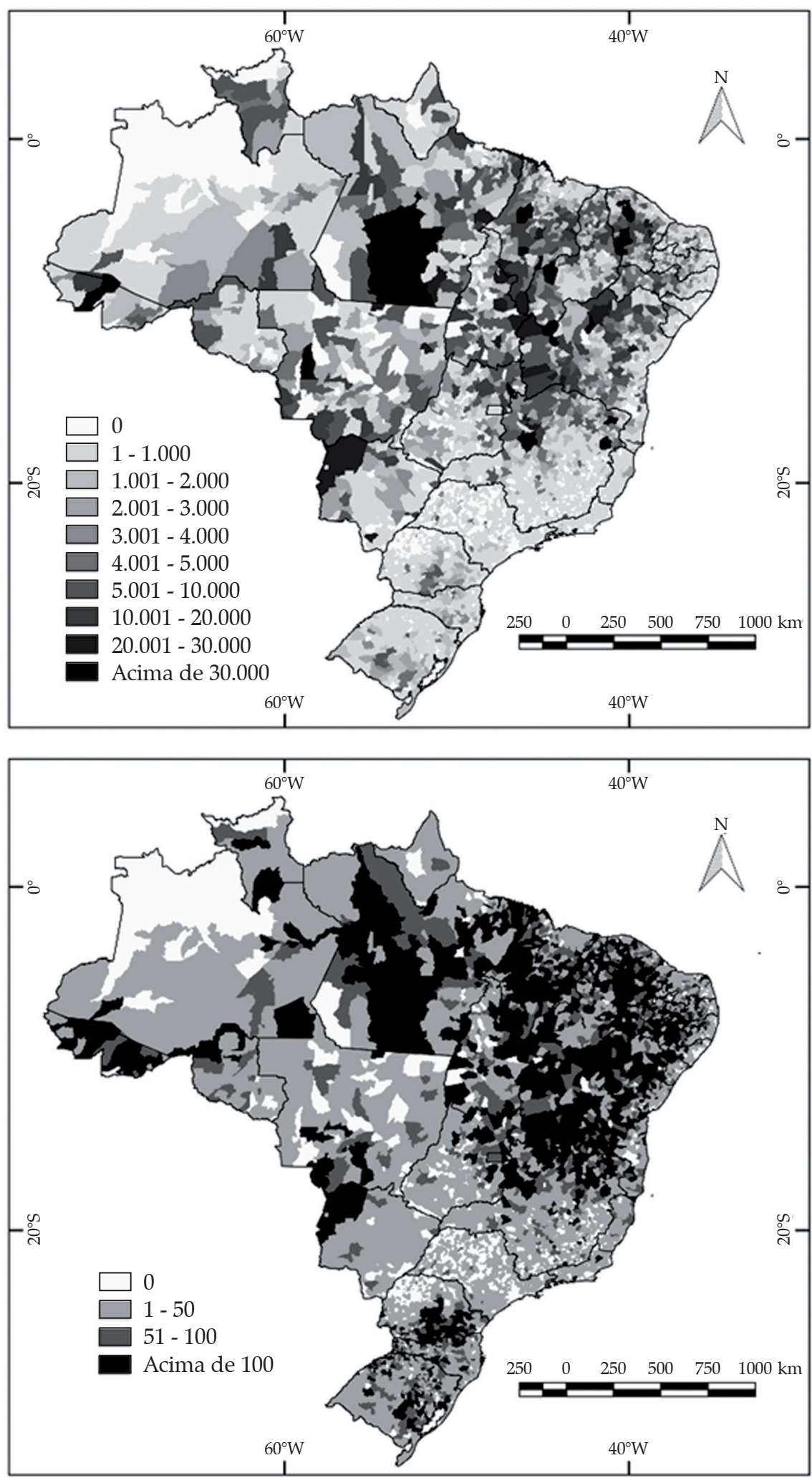

Fonte: Censo Agropecuário (IBGE, 2006). 
Deve-se destacar que $26 \%$ das propriedades com uso de SAF's têm menos de 10 hectares, $45 \%$ têm entre 10 e 50, e $29 \%$ têm mais de 50 (IBGE, 2006). Esses valores confirmam a hipótese de Mbow et al. (2014b), que apontam que até mesmo pequenos agricultores têm possibilidade de adotar o sistema. Os achados dos estudos de caso de Dos Santos et al. (2014) e Pompeu et al. (2012) também encontram respaldo nos dados do Censo Agropecuário 2006 (IBGE, 2006), já que a maior parte das propriedades com SAF's é administrada por agricultores que possuem título de propriedade da terra $(87 \%)$ e que têm mais de 10 anos de experiência com atividades agrícolas. Parcela expressiva desses agricultores (48\%) também é associada a algum tipo de cooperativa ou entidade de classe (sindicatos e, ou, associações/ movimentos de produtores).

\section{Metodologia}

\subsection{Modelo de efeito de tratamento e Propensity Score Matching}

Para responder às questões propostas neste estudo é preciso comparar municípios nos quais houve diversificação por meio de SAF's com aqueles em que esse tipo de técnica agrícola não foi utilizada. ${ }^{9}$ Supõe-se, inicialmente, que $y_{1 i, t}$ denote os ganhos médios resultantes da atividade agrícola no município $i$ onde houve a prática de SAF's em determinado período de tempo $t$; igualmente, $y_{0, t}$ representa os ganhos em um município no qual SAF's não foram utilizados, no mesmo período $t$. A diferença entre os ganhos obtidos pelos dois diferentes municípios, $y_{1, t}-$ $y_{0 i, t}$, é definida como o impacto econômico que a

9. O modelo empírico foi desenvolvido em nível municipal pois o Censo Agropecuário, principal base de dados brasileira que contempla as variáveis necessárias para essa pesquisa, não fornece estatísticas em nível de produtor com a identificação das coordenadas geográficas de latitude e longitude (para preservar a identidade dos respondentes do Censo). Diante disso, não é possível atribuir valores das variáveis climáticas a cada produtor, o que inviabiliza o estudo do efeito das mudanças climáticas. adoção de um SAF tem sobre os municípios nos quais essa forma de exploração agrícola foi utilizada. Tecnicamente, tem-se o Efeito do Tratamento Médio sobre o Tratado - ETM:

$$
\mathrm{ETM}=E\left(y_{1 i}-y_{0 i} \mid D=1\right)
$$

em que $E\left(y_{1 i}-y_{0 i}\right)$ refere-se à expectativa do efeito do tratamento; e $D=1$ identifica a adoção de SAF's.

Como se trata de uma comparação no mesmo período $t$, não é possível observar $y_{0 i, t}$ para o município onde há SAF's, tampouco $y_{1 i, t}$ para municípios sem nenhuma área com uso dessa técnica. Dessa forma, é preciso usar como controle um grupo de municípios nos quais os SAF's não tenham sido praticados, mas que tenham características semelhantes aos que possuem áreas cultivadas com SAF's. Define-se, portanto, um contrafactual que permite identificar qual seria o ganho médio dos municípios nos quais há agricultores que se diversificaram por meio de SAF's, caso eles não tivessem nenhuma área dedicada a esse sistema. ${ }^{10}$

A obtenção do contrafactual pode ser realizada por meio da técnica de Propensity Score Matching (PSM), proposta por Rosenbaum e Rubin (1983). Conforme os autores, o escore de propensão é definido como a probabilidade condicional de receber o tratamento, dadas as características pré-estabelecidas:

$$
p(W) \equiv \operatorname{Pr}(D=1 \mid W)=E(D \mid W)
$$

em que $D=(1,0)$ é a dummy indicadora de utilização de SAF's (tratamento) e $W$, o vetor multidimensional de características antes do tratamento (tipos de solos, temperatura e precipitação, fatores demográficos, socioeconômicos e estruturais dos municípios).

\footnotetext{
10. Ressalta-se que a simples comparação de municípios com e sem áreas cultivadas com SAF's geraria resultados viesados. Isso ocorre pois a decisão de cultivar utilizando SAF's não é aleatória. Agricultores tomam essa decisão num processo de maximização de benefícios, o que caracteriza a existência de autosseleção.
} 
Considerando cada município $i$, se o escore de propensão, $p\left(W_{i}\right)$, é conhecido, então o ETM pode ser estimado da seguinte maneira:

$$
\begin{aligned}
E T M_{1} & =\left\{y_{1 i}-y_{0 i} \mid D_{i}=1\right\} \\
& =E\left[E\left\{y_{1 i}-y_{0 i} \mid D_{i}=1, p\left(W_{i}\right)\right\}\right] \\
& =E\left[E\left\{y_{1 i} \mid D_{i}=1, p\left(W_{i}\right)\right\}-E\left\{y_{0 i} \mid D_{i}=0, p\left(W_{i}\right)\right\} \mid D i=1\right]
\end{aligned}
$$

Para a estimação do escore de propensão $p\left(W_{i}\right)$ deve ser utilizado um modelo de probabilidade, $\operatorname{Pr}\left(D_{i}=1 \mid W_{i}\right)=F\left\{h\left(W_{i}\right)\right\}$. Neste trabalho, utilizou-se o modelo Probit, de modo que $F($.) é a distribuição normal. Adicionalmente, para a construção do grupo de comparação a partir dos municípios não tratados (sem SAF's), foi utilizado o método Kernel. Por meio desse método todos os tratados são comparados com a média ponderada de todos os controles, com pesos que são inversamente proporcionais à distância entre os escores de propensão dos tratados e dos controles (BECKER e ICHINO, 2002). ${ }^{11}$

A variável indicativa dos ganhos médios resultantes da atividade agrícola $\left(y_{1 i, t}\right.$ e $\left.y_{0, t}\right)$ foi representada pelo valor médio da terra, de forma similar aos estudos de Mendelsohn et al. (1994), Pires e Cunha (2014) e Cunha et al. (2015). Para isso, pressupóe-se que, sob mercados competitivos, o valor da terra será igual à receita líquida do seu melhor uso, já que os produtores sempre praticarão a atividade mais lucrativa. Ao considerar o preço da terra, o modelo estima diretamente os impactos do clima sobre a produtividade de distintas culturas e, indiretamente, a substituição de insumos e a introdução de diferentes técnicas produtivas e outras potenciais medidas de mitigação e adaptação. $\mathrm{O}$ modelo permite medir o impacto das mudanças climáticas sobre o valor econômico de diferentes atividades (MENDELSOHN et al., 1994). Portanto, a redução da vulnerabilidade será avaliada por meio da eficácia dos SAF's em garantir maiores valores da terra nos municípios que adotam o sistema.

Para caracterizar os elementos presentes no vetor $W_{i}$, o qual representa os determinantes da

11. A metodologia dessa seção é resumida na Figura A1, apresentada no Anexo, na qual são descritas as estratégias empíricas utilizadas para a obtenção dos resultados. adoção de SAF's, foi utilizada a abordagem teórica proposta por Yohe e Tol (2002). Segundo os autores, existem oito determinantes da adoção de estratégias adaptativas: (1) variedade de opções tecnológicas disponíveis (neste estudo refere-se à utilização de SAF's); (2) disponibilidade de recursos naturais e sua distribuição entre a população/ território; (3) estrutura de instituições facilitadoras, bem como suas regras e critérios de concessão de recursos; (4) estoque de capital humano, incluindo educação; (5) estoque de capital social, incluindo a definição dos direitos de propriedade; (6) facilidade de acesso a mecanismos de redução de riscos; (7) capacidade dos tomadores de decisão para gerir informação e disponibilidade de informações críveis e (8) percepção e grau de exposição do público em relação aos processos causadores de estresse do sistema (mudança climática). É importante destacar que a metodologia de Yohe e Tol (2002) guarda relação direta com os fatores condicionantes da adoção de SAF's descritos na seção 2 do presente estudo.

\subsection{Simulações de mudanças climáticas}

A etapa inicial do estudo, descrita na seção anterior, permitiu responder à primeira questão de pesquisa e parte da segunda. Sendo assim, nessa seção são descritas as simulações realizadas para analisar o potencial dos SAF's de diminuir a vulnerabilidade agrícola em cenários futuros de mudança climática, o que completa a proposta do estudo.

Para realizar as simulações, partiu-se do cálculo do ETM realizado para as variáveis no período $t$ (presente) (equação 3), mas utilizando projeções de temperatura e precipitação para a média de dois períodos de tempo propostos pelo IPCC (2013): 2016-2035 e 2046-2065. Desse modo, calcularam-se novos efeitos de tratamento, considerando a diferença no valor da terra dos municípios com e sem áreas cultivadas com $\mathrm{SAF}^{\prime}$ s. Seguindo o procedimento descrito em Mendelsohn et al. (1994), que é comum em estudos que tratam de mudanças climáticas, as simulações foram realizadas mantendo constantes as 
variáveis agronômicas e socioeconômicas. Esse procedimento é feito para contabilizar apenas o efeito das mudanças climáticas.

A partir dos valores do ETM simulados em cada um dos dois períodos futuros para cada tipo de município, obteve-se a variação percentual dos valores da terra em relação ao período atual, com o intuito de analisar possíveis ganhos ou prejuízos resultantes das mudanças climáticas. Nesse procedimento foi utilizada a seguinte fórmula:

$$
\Delta V \hat{T}=\frac{V \hat{T}_{T i}^{m}-V \hat{T}_{\text {presente }}^{m}}{V \hat{T}_{\text {presente }}^{m}} \cdot 100
$$

em que $\Delta V \hat{T}^{m}$ refere-se à variação percentual do valor da terra estimado, entre o período Ti (20162035 ou 2046-2065) e o período $t$ (presente), para cada tipo de município $m$ (com ou sem uso de SAF's).

As projeções de temperatura e precipitação utilizadas neste estudo foram feitas a partir dos Representative Concentration Pathways (RCP) propostos pelo IPCC (2013). Foram considerados dois cenários climáticos, sendo um com expectativa intermediária de mudança climática (RCP 4.5) e outro pessimista (RCP 8.5). ${ }^{12}$

\subsection{Fonte dos dados e variáveis utilizadas}

Os oito determinantes do investimento em adaptação às mudanças climáticas propostos por Yohe e Tol (2002) podem ser pensados, de modo geral, como disponibilidade de recursos econômicos e naturais, opções tecnológicas, informações e habilidades, infraestrutura e instituições. No presente estudo, esses determinantes foram organizados em três categorias de variáveis, cujas fontes dos dados utilizados na sua construção são descritas a seguir:

12. Detalhes sobre os cenários climáticos podem ser obtidos em IPCC (2013). As etapas referentes às simulações de mudança climática são sintetizadas na Figura A2, apresentada no Anexo, que complementa a estratégia empírica descrita na Figura A1.
1. Variáveis climáticas: temperatura e precipitação (valores do período atual e de cenários futuros) - Base CRU Times Series 3.2.1 do Climate Research Unit (CRU/ University of East Anglia, 2013) e Modelos de Circulação Geral - IPCC (2013) (Model for Interdisciplinary Research on Climate, version 5 - MIROC5; Meteorological Research Institute Coupled Atmosphere-Ocean General Circulation Model, version 3 - MIR-CGCM3; Norwegian Earth System Model, version 1 - NorESMI1-M; e Hadley Global Environment Model 2 Earth System - HadGEM2-ES).

2. Variáveis socioeconômicas: acesso à informação e opções de financiamento, propriedade da terra, participação em associações de classe etc. - Censo Agropecuário 2006 (IBGE, 2006) e Observatório ABC (Fundação Getúlio Vargas).

3. Variáveis agronômicas: potencial agrícola do solo dos municípios - Mapa do Potencial Agrícola do Brasil - IBGE (2002).

O Quadro 1 a seguir, descreve e sintetiza as variáveis utilizadas no estudo e suas fontes, considerando a abordagem teórica de Yohe e Tol (2002) e a revisão de literatura apresentada na seção 2 .

Optou-se por considerar apenas a média anual de temperatura e a precipitação, ao invés das quatro estações do ano. De acordo com Seo (2011), esse tipo de especificação é mais adequada nas análises referentes aos países da América do Sul, já que nessa região as estações não são tão bem definidas como no hemisfério Norte. Além disso, supondo que a relação entre as variáveis climáticas e a produtividade das culturas seja caracterizada por não linearidades, incluiu-se também os termos quadráticos dessas variáveis.

A variável socioeconômica Informação, representativa do acesso à informação e do estoque de conhecimento dos produtores rurais do município [determinantes (4) e (7) do modelo de Yohe e Tol (2002)] foi construída a partir da técnica de análise multivariada conhecida como Análise de Componentes Principais (ACP). Trata-se de uma 


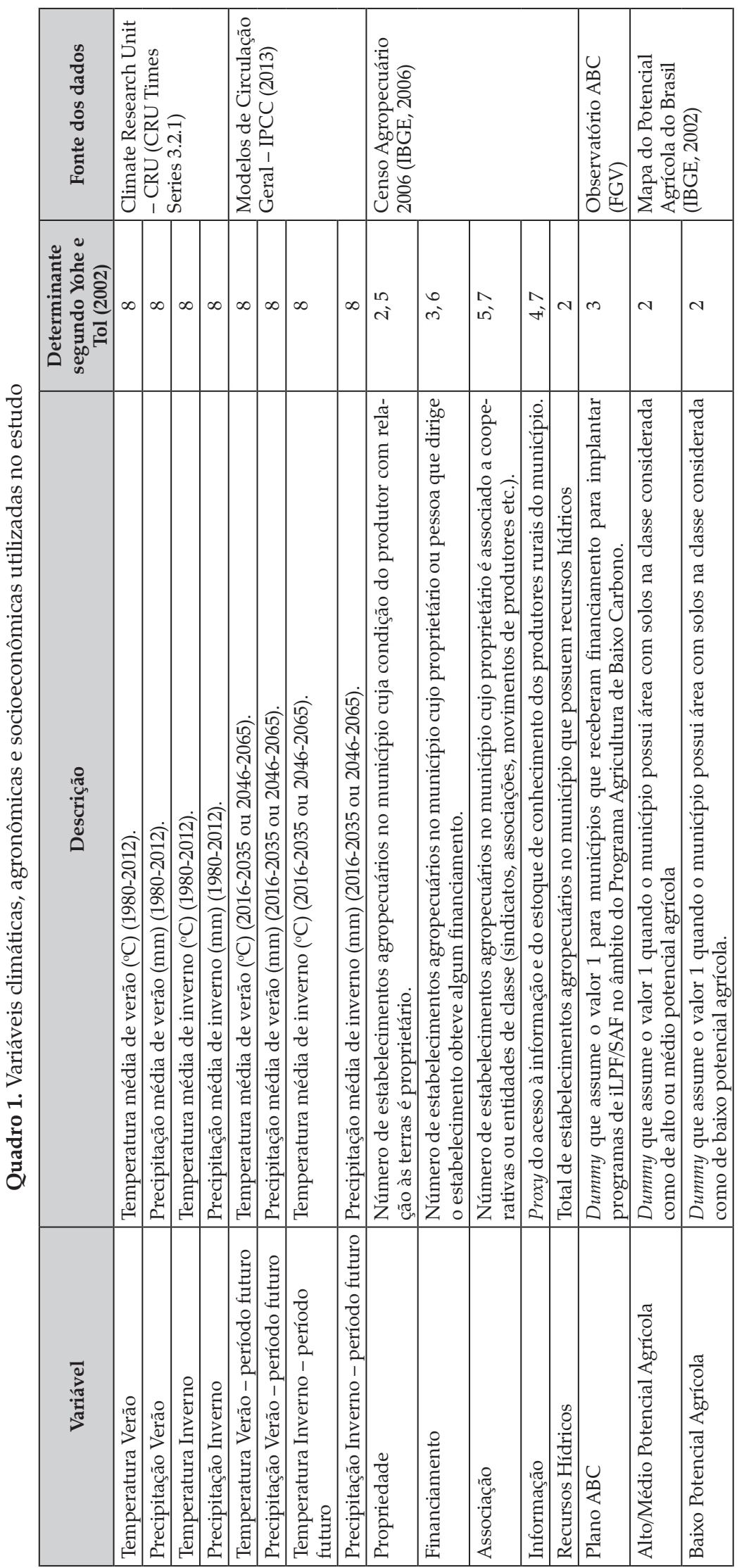

RESR, Piracicaba-SP, Vol. 55, № 01, p. 009-030, Jan./Mar. 2017 - Impressa em Junho de 2017 
técnica que consiste em transformar um conjunto original de variáveis em outro conjunto - os Componentes Principais ( $\left.\mathrm{CP}^{\prime} \mathrm{s}\right)$. Os CP's são combinações lineares das variáveis originais e são estimados de forma a captar o máximo da variação total dos dados (MINGOTI, 2005). Dessa forma, a variável Informação é um CP que considera i) o número de produtores no município com ensino superior, médio e técnico agrícola completo, ii) o número de produtores no município que recebeu visitas regulares de técnicos agrícolas, iii) o número de produtores no município que têm 10 anos ou mais de experiência na atividade agrícola e iv) o número de produtores no município com acesso a televisão, rádio, computador e internet. Todas essas variáveis estão disponíveis no Censo Agropecuário 2006 (IBGE, 2006) e sua escolha foi realizada seguindo o modelo teórico de Yohe e Tol (2002) e as discussões da literatura especializada (McGINTY et al., 2008; GONÇALVES e VIVAN, 2012; POMPEU et al., 2012; DOS SANTOS et al., 2014; MEIJER et al., 2015a, 2015b). ${ }^{13}$

No que diz respeito à representação das características agronômicas dos municípios, optou-se por incluir, assim como no estudo de Cunha et al. (2015), apenas duas entre as oito categorias disponíveis no Mapa do Potencial Agrícola do Brasil, disponibilizado pelo IBGE (2002): solos com alto/ médio potencial agrícola e solos com baixo potencial agrícola. ${ }^{14}$ Segundo o IBGE (2002), a definição dessas categorias é feita levando em conta fatores como fertilidade, características físicas e morfológicas, principais limitações e topografia.

Por fim, para a determinação dos municípios incluídos na pesquisa foi considerada a malha municipal 2007, fornecida pelo IBGE. Por diferentes razões algumas exclusões foram realizadas. Inicialmente, foram desconsideradas as 26 capitais estaduais e o Distrito Federal, já que, segundo Schlenker et al. (2005), a forte influência da urbanização sobre os valores das terras nessas

13. Os resultados da ACP são apresentados no Anexo.

14. As oito categorias de aptidão agrícola são: 1. Boa; 2. Boa/ Regular; 3. Regular/Média; 4. Regular; 5. Regular/Restrita; 6. Restrita; 7. Restrita/Desfavorável; 8. Desaconselhável. localidades poderia viesar os resultados. Também foram excluídos os municípios para os quais o banco de dados do Censo Agropecuário não registrava os valores da terra ou de alguma outra variável do conjunto de regressores. Finalmente, a ilha de Fernando de Noronha também foi excluída por não ter representatividade no contexto da produção agrícola nacional. A amostra final contou com 5485 municípios.

\section{Resultados}

\subsection{Análise descritiva das variáveis}

Inicialmente, procurou-se apresentar as estatísticas descritivas das variáveis utilizadas no modelo, ou seja, as características socioeconômicas, as condições climáticas e do solo dos municípios brasileiros (Tabela 1). Esse foi o primeiro passo para o entendimento dos condicionantes e barreiras à adoção de SAF's no Brasil. Essa análise exploratória fornece subsídios gerais para o entendimento dos resultados do modelo de efeito de tratamento que serão apresentados na próxima seção.

É importante esclarecer que a área média utilizada com SAF's nos municípios do País situa-se em torno de 2.000 hectares, o que ainda é muito baixo em face das metas da Política Nacional sobre Mudanças do Clima. ${ }^{15}$ Dos 5.485 municípios considerados na pesquisa, 4.351 foram identificados pelo Censo Agropecuário como tendo áreas cultivadas com uso de SAF's. Entre esses, apenas $23 \%$ apresentam valores de área maiores que a média nacional.

Observa-se que a média das temperaturas a que estão expostos os municípios com uso de SAF's é maior e estatisticamente diferente do que a observada nos municípios sem uso da técnica (Tabela 1). Ademais, esses valores tendem a ser mais altos para municípios que têm mais de 2.000 hectares, em média, cultivados com SAF's.

15. O valor exato da área média municipal é de 1.890,1 hectares, conforme dados do Censo Agropecuário 2006. 
Tabela 1. Estatísticas descritivas das variáveis utilizadas no estudo, considerando municípios com e sem uso de sistemas agroflorestais

\begin{tabular}{|c|c|c|c|c|c|c|}
\hline \multirow{2}{*}{ Variáveis } & \multicolumn{2}{|c|}{ Com SAF $(<2.000$ ha $)$} & \multicolumn{2}{|c|}{ Com SAF (> 2.000 ha) } & \multicolumn{2}{|c|}{ Sem SAF's } \\
\hline & Média & Desvio Padrão & Média & Desvio Padrão & Média & Desvio Padrão \\
\hline Temperatura*** & 23,00 & 2,90 & 25,20 & 2,22 & 22,94 & 2,38 \\
\hline Precipitação*** & 120,15 & 37,45 & 105,46 & 46,64 & 127,08 & 29,09 \\
\hline Propriedade ${ }^{* * *}$ & 492,36 & 461,24 & 766,41 & 768,01 & 180,06 & 193,48 \\
\hline Financiamento*** & 182,61 & 215,25 & 237,36 & 284,94 & 59,77 & 78,04 \\
\hline Associação*** & 265,26 & 363,63 & 618,08 & 732,10 & 124,89 & 163,43 \\
\hline Plano ABC ${ }^{* * *}$ & 0,04 & 0,18 & 0,05 & 0,22 & 0,01 & 0,13 \\
\hline Informação*** & 0,08 & 1,01 & 0,26 & 1,21 & $-0,45$ & 0,54 \\
\hline Recursos Hídricos*** & 612,32 & 527,16 & 892,00 & 771,08 & 261,86 & 246,14 \\
\hline Alto/Médio Potencial Agrícola*** & 0,11 & 0,31 & 0,14 & 0,35 & 0,20 & 0,40 \\
\hline Baixo Potencial Agrícola & 0,74 & 0,44 & 0,75 & 0,43 & 0,72 & 0,44 \\
\hline Valor da Terra ${ }^{* * *}$ & $154.179,6$ & $222.827,7$ & $216.070,9$ & $382.190,7$ & $120.975,6$ & $154.805,1$ \\
\hline
\end{tabular}

Notas: A variável Valor da Terra está cotada em mil reais (valores referentes ao Censo Agropecuário de 2006); (**) indica que as médias são estatisticamente diferentes a 1\% de acordo com o teste de média para amostras múltiplas de Krishnamoorthy e Yu (2004).

Fonte: Resultados da Pesquisa.

Isso pode ser um primeiro indício de que essa forma de exploração agrícola é utilizada como medida adaptativa às alterações climáticas. Os SAF's são responsáveis pelo desenvolvimento de microclima favorável à atividade biológica, proporcionando diminuição da energia radiante, do movimento do ar, da evapotranspiração e da temperatura máxima do ar, o que ocasiona a diminuição da temperatura da superfície (BALBINO et al., 2012). Além disso, alguns estudos apontam que $\mathrm{SAF}^{\prime}$ s propiciam maior conforto térmico para os animais e, ao mesmo tempo, garantem maior produtividade e rentabilidade para o produtor (LEME et al., 2005; PIRES et al., 2008; MELLACE, 2009).

Os valores de precipitação, por sua vez, indicam que os municípios com SAF's estão submetidos a menores médias de chuvas quando comparados aos que não utilizam a técnica (Tabela 1). As consequências advindas das mudanças climáticas na distribuição das chuvas, na temperatura e outros fatores que interfiram no ciclo de produção e na vegetação podem implicar menores safras e baixa qualidade dos produtos (IPCC, 2014). Dessa forma, além de prejudicar a agricultura, alterações nos padrões climáticos podem representar risco à segurança alimentar e à permanência dos agricultores no campo. Diante disso, a estratégia de adoção de SAF's nos muni- cípios onde foram constatadas menores médias de precipitação pode ser um indício de adaptação às condições climáticas que eram prejudiciais à eficiência produtiva.

No que se refere às condições socioeconômicas municipais, os dados permitem inferir que a média das variáveis 'Financiamento', 'Associação', 'Plano ABC' e 'Informação' foram superiores nos municípios em que há áreas cultivadas com SAF's (Tabela 1). Isso evidencia que esses são fatores importantes na decisão de adoção, o que é condizente com a literatura acerca do assunto (MEIJER et al., 2015a). Perante a complexidade das atividades envolvidas no SAF, fatores como o domínio da tecnologia de lavouras anuais e pecuária, máquinas e equipamentos agrícolas mais diversificados, assim como conhecimento mais apurado do mercado agropecuário, tornam-se decisivos para a difusão e expansão desse tipo de sistema de produção agrícola. Além disso, o conhecimento dos benefícios econômicos, sociais e ambientais da técnica, através, por exemplo, de associação a cooperativas também se constituiriam em incentivos à adoção. Municípios nos quais há muitos agricultores com facilidade de acesso a opções de financiamento e maior familiaridade com o processo produtivo, têm mais chances de possuir áreas cultivadas com SAF's 
(MACEDO, 2001; GONÇALVES e VIVAN, 2012; POMPEU et al., 2012; DOS SANTOS et al., 2014). Ainda conforme os dados da Tabela 1, parece haver relação positiva entre municípios nos quais há utilização de SAF's e aqueles onde é maior o número de estabelecimentos agropecuários cuja condição do produtor com relação às terras é proprietário.

Pelos dados da Tabela 1 também é possível verificar que, em municípios nos quais não há áreas cultivadas com SAF's, há menor disponibilidade de recursos hídricos e o percentual da área de solo com potencialidade agrícola na classe média/alta é inferior. Conforme Balbino et al. (2011), o conjunto de práticas possibilitadas pelos SAF's atuam como ferramentas importantes para a diminuição da degradação de solos ao permitir a recuperação sustentável de seu potencial produtivo. Ademais, o uso de SAF's, mesmo em locais que apresentem baixo potencial agrícola, poderia trazer benefícios ao produtor em termos de melhoria da qualidade do solo e conservação de água (LASCO et al., 2014).

Por fim, as estatísticas descritivas apresentadas na Tabela 1 a respeito da variável 'Valor da Terra' sugerem que os ganhos médios resultantes da atividade agrícola são maiores quanto maior é a área cultivada com sistemas integrados. Nos munícipios onde a área com SAF's é maior do que 2.000 hectares, o valor médio da terra é cerca de $78 \%$ mais elevado do que nas localidades que não contam com essa técnica de exploração agrícola. O mesmo vale para os municípios com menos de 2.000 hectares cultivados com SAF's, nos quais o valor médio da terra é $27 \%$ maior.

\subsection{Análise dos fatores associados à decisão de utilização de $S A F^{\prime}$ s}

Após a análise descritiva das variáveis utilizadas no modelo, são apresentadas as estimativas do modelo Probit que visam explicar os fatores associados à decisão de adoção de SAF's (Tabela 2). Essa estimação possibilita responder a primeira questão de pesquisa deste estudo e é, ao mesmo tempo, a etapa inicial para a comparação dos municípios que possuem áreas com SAF's e aqueles nos quais esse sistema não está presente (Modelo de Efeito de Tratamento). Tal comparação permitirá responder concretamente a segunda questão de interesse nesta pesquisa, qual seja, o papel de SAF's como medida de adaptação aos efeitos adversos das mudanças climáticas.

Tabela 2. Estimativas do modelo Probit de determinação da probabilidade de adotar sistemas agroflorestais no Brasil

\begin{tabular}{|c|c|c|c|c|}
\hline \multirow{2}{*}{ Variáveis } & \multicolumn{2}{|c|}{ Modelo 1} & \multicolumn{2}{|c|}{ Modelo 2} \\
\hline & Coeficiente & P-valor & Coeficiente & P-valor \\
\hline Temperatura & $-2.1947^{* * *}$ & 0.0000 & $-1.9362^{* * *}$ & 0.0000 \\
\hline Temperatura2 & $0.0476^{* * *}$ & 0.0000 & $0.0426^{* * *}$ & 0.0000 \\
\hline Precipitação & $-0.0271^{* * *}$ & 0.0000 & $-0.0196^{* * *}$ & 0.0000 \\
\hline Precipitação2 & $0.0001^{* * *}$ & 0.0000 & $0.0001^{* * *}$ & 0.0000 \\
\hline Propriedade & & & $0.0005^{*}$ & 0.0980 \\
\hline Financiamento & & & $0.0009^{* * *}$ & 0.0060 \\
\hline Associação & & & $0.0005^{* *}$ & 0.0280 \\
\hline Plano ABC & & & -0.0072 & 0.9620 \\
\hline Informação & & & $0.1757^{* * *}$ & 0.0020 \\
\hline Recursos Hídricos & & & $0.0011^{* * *}$ & 0.0000 \\
\hline Baixo Potencial Agrícola & & & -0.0304 & 0.5780 \\
\hline Médio/Alto Potencial Agrícola & & & $-0.4662^{* * *}$ & 0.0000 \\
\hline Intercepto & $27.7593^{* * *}$ & 0.0000 & $23.3394^{* * *}$ & 0.0000 \\
\hline
\end{tabular}

Notas: No Modelo 1 houve a previsão correta de $79,3 \%$ dos valores observados e no Modelo 2 esse valor foi de $83,1 \% ;\left(^{* * *}\right),\left({ }^{* *}\right)$ e $\left(^{*}\right)$ indicam significância a 1\%,5\% e 10\%, respectivamente (P-valor baseado em desvio padrão obtido após a correção de heterocedasticidade).

Fonte: Resultados da pesquisa. 
Pode-se verificar na Tabela 2 que a adoção de SAF's é sensível tanto à temperatura quanto à precipitação, o que valida o uso do sistema como mecanismo adaptativo às alterações dos padrões climáticos. A análise simultânea dos termos linear e quadrático das variáveis climáticas revela um padrão em forma de $U$ para a probabilidade de o município utilizar SAF's. Dessa forma, a partir de certo nível de temperatura e pluviosidade, a probabilidade de adoção de SAF's aumenta.

No caso da temperatura, os resultados da Tabela 2 evidenciam o papel dos SAF's como estabilizador térmico, visto que plantas e animais possuem limites de tolerância ao calor. $\mathrm{O}$ aumento de temperatura leva a aumentos da evapotranspiração das plantas, o que depende, dentre outros fatores, da capacidade hídrica do solo. De acordo com Primavesi et al. (2007), existe um ótimo para a respiração das plantas, de forma que o aumento da temperatura ocasionalmente acarreta aumento da respiração e, sem que haja hidratação suficiente, os danos podem ser irrecuperáveis. Ao mesmo tempo, conforme Bridi (2000), em caso de distúrbios térmicos, os animais precisam aumentar a perda de calor corporal e diminuir a produção, reduzindo a energia que seria utilizada para produção ou reprodução. Ademais, segundo Primavesi et al. (2007), o componente arbóreo de um SAF é eficiente para conter o aquecimento, por funcionar como estabilizador térmico e formador de interceptação de radiação solar.

Com relação às variáveis de precipitação, os resultados da Tabela 2 também encontram respaldo na análise de Primavesi et al. (2007). Segundo os autores, os resíduos vegetais conseguem interceptar e armazenar águas pluviais. Os autores consideram ainda que o sistema integrado, que possui elevada biodiversidade e extensas estruturas radiculares, além de reduzir os impactos da elevação de temperatura, consegue diminuir o impacto de chuvas tropicais, reduzindo a velocidade de escoamento superficial da água. Em sistemas especializados de agricultura ou pecuária, o escoamento da água de chuvas tropicais é dez vezes maior do que em sistemas integrados, causando enchentes e rebaixamento do lençol freático e, assim, perdendo a capacidade hídrica que deveria abastecer a vegetação em períodos mais secos (PRIMAVESI et al., 2007).

A avaliação dos resultados encontrados em relação às características socioeconômicas municipais permite inferir que as variáveis 'Propriedade', 'Financiamento', 'Associação' e 'Informação' afetam positivamente a probabilidade de existência de áreas cultivadas com a utilização de SAF's (Tabela 2).

O fato de um município com grande número de agricultores que são proprietários dos estabelecimentos agropecuários ter maior probabilidade de apresentar áreas cultivadas com SAF's faz sentido na medida em que produtores com essas características são mais propensos a incorrer no risco de optar pelo sistema. A propriedade da terra estimula a busca por opções que possam melhorar os rendimentos. Segundo Motta (2011), a comprovação do vínculo do agricultor com a terra é um aspecto relevante no acesso às linhas de crédito - tais como o Programa Nacional de Fortalecimento da Agricultura Familiar (Pronaf) e o Plano ABC. Além disso, apesar de não obrigatória, a apresentação do título de propriedade acelera o processo de obtenção das linhas de crédito públicas e também contribui como garantia para empréstimos particulares.

O efeito positivo e significativo da variável socioeconômica 'Financiamento' (Tabela 2) também é condizente com a expectativa da literatura que trata de adaptação às mudanças climáticas (BELOW et al., 2012; CUNHA et al., 2015). A obtenção de crédito é importante fator para que agricultores integrem e diversifiquem os seus sistemas de produção. Contando com aporte financeiro, os produtores podem modernizar os seus estabelecimentos de forma que se aliem maiores rendimentos, eficiência produtiva, sustentabilidade, além da "segurança econômica" resultante da diversificação das atividades.

A variável 'Associação' diz respeito ao número de produtores que são associados a cooperativas ou associações de classe no município. Nesse sentido, o sinal positivo (Tabela 2) pode ser explicado 
pelo fato de esse tipo de produtor ter potencialmente maior acesso a informações sobre a utilização da técnica, além da possibilidade do compartilhamento de experiências e conhecimentos com outros produtores que utilizaram o sistema. Ademais, segundo Abdo et al. (2008), as associações de produtores em geral fornecem insumos a preços mais competitivos, ajudam no uso racional de equipamentos, racionalizam as atividades pós-colheita e contribuem no processo de comercialização. Esses autores também ressaltam que no momento de implantação de SAF's há grande demanda de mão de obra e, assim, a prática de mutirões de produtores com culturas semelhantes nos SAF's pode ser eficiente (ABDO et al., 2008).

A variável 'Informação', que no presente estudo está relacionada ao estoque de capital humano e ao acesso a informações, foi significativa e positivamente relacionada à adoção de SAF's (Tabela 2). Nesse caso, quanto maior o nível de educação, experiência dos produtores, acesso à assistência técnica e meios de comunicação, maior a probabilidade de o município apresentar áreas cultivadas com sistemas agrícolas mais sustentáveis. Tal resultado é respaldado pelos estudos de He et al. (2007), Bellow et al. (2012) e Cunha et al. (2015). A partir da análise desses autores, pode-se inferir que, em municípios cujos agricultores apresentam maior nível de capital humano, há, em geral, mais probabilidade de implantação de SAF's.

Ainda sobre a variável 'Informação' é preciso fazer outras importantes considerações. No presente estudo, para a construção da variável, foi considerado, dentre outros fatores, o número de produtores no município que recebeu visitas regulares de técnicos agrícolas e o número de agricultores com ensino superior ou curso técnico agrícola. A influência da escolaridade e assistência técnica sobre a adaptação se dá por duas vias, segundo Wamsler et al. (2012). Ambas têm efeito direto sobre a redução dos riscos associados aos eventos climáticos extremos, pois possibilitam maior conhecimento de mecanismos e processos que reduzam a vulnerabilidade a esses eventos e, além disso, permitem que o agricultor ou agente envolvido conheça e adote estratégias de adaptação. São, portanto, fundamentais para a difusão de tecnologias no meio rural. Entretanto, conforme o relatório "Propostas para a revisão do Plano ABC" (OBSERVATÓRIO ABC, 2015), o investimento em treinamento de técnicos e extensionistas para trabalhar com as tecnologias do Plano $A B C$ tem sido aquém do programado. Isso pode estar comprometendo a expansão das áreas de SAF's no Brasil. Segundo o relatório, a capacitação de operadores de crédito rural, elaboradores de projetos, técnicos e extensionistas rurais é fundamental, pois tais agentes atuam desde o momento da contratação do financiamento e, principalmente, ao longo da execução do projeto.

Considerando as condições agronômicas dos municípios avaliados (Tabela 2), ressalta-se que o resultado para a variável referente aos solos com média/alta potencialidade agrícola indicou que a existência desse tipo de solo reduz a probabilidade de adotar SAF's. Embora esse resultado pareça, a princípio, contraditório, é importante notar que sistemas integrados têm o potencial para aumentar a fertilidade dos solos em decorrência do incremento das taxas de matéria orgânica e nutrientes, bem como aumentos na capacidade de troca catiônica (GARRITY, 2004). Ademais, os SAF's são capazes de reduzir os processos erosivos e aumentar a capacidade de retenção de umidade do solo, promovendo sua estabilização (GARRITY, 2004). Dessa forma, municípios com solos de melhor qualidade poderiam ter menor probabilidade de utilização da técnica em relação àqueles cujas condições de solo são piores.

\subsection{Efeito do uso de SAF's sobre o desempenho dos municípios no período atual e em cenários de mudanças climáticas}

Após as considerações a respeito dos determinantes da adoção de SAF's no Brasil, avaliou-se as diferenças de desempenho agrícola em municípios com e sem uso de SAF's, o que permite avaliar o potencial de redução da vulnerabilidade 
às mudanças climáticas dessa técnica de exploração agrícola. Para tal, o modelo Probit, cujos resultados foram apresentados na seção anterior, foi utilizado para realizar o pareamento entre municípios nos quais há áreas com uso de SAF's e aqueles em que não há essa forma de exploração agrícola, mas que possuem probabilidade de utilização semelhante - cálculo do valor $p\left(W_{i}\right)$ na equação 3. Esse pareamento permitiu o cálculo do Efeito do Tratamento Médio sobre o Tratado (ETM). Neste estudo, a variável de interesse foi o valor da terra (Tabela 3).

Na Tabela 3 pode-se observar que o valor da terra nos municípios com uso de SAF's foi superior ao dos municípios nos quais essa técnica não é utilizada, tanto no presente quanto nas simulações considerando os cenários climáticos futuros. As diferenças calculadas são estatisticamente significativas a $1 \%$ de probabilidade. Esses resultados indicam que, se os atuais municípios com uso de SAF's deixassem de utilizar esse sistema de produção, poderiam ter retornos $8,2 \%$ inferiores no presente. Se forem contabilizadas as variações no valor da terra para cada tipo de técnica de produção, conforme a equação 4 descrita na metodologia, verifica-se que os municípios com SAF's podem ter ganhos de até 8,7\% (2016-2035; RCP 4.5); ao mesmo tempo, para os municípios nos quais não há nenhuma área cultivada com o uso de SAF's espera-se perdas de até 19,7\% (2016-2035; RCP 8.5). Confirma-se que o uso de $\mathrm{SAF}^{\prime}$ s tem potencial para melhorar o desem- penho agrícola do País, reduzindo a vulnerabilidade às variações do clima. Esses resultados estão em conformidade com estudos realizados para outras regióes, tais como os de Luedeling et al. (2014), Mbow et al. (2014a, 2014b), Lasco et al. (2014), Hedge e Bull (2011) e Pagiola et al. (2008).

De acordo com Lasco et al. (2014), SAF's são cada vez mais reconhecidos como forma sustentável de uso da terra em paisagens multifuncionais. Tais sistemas aumentam a capacidade dos agricultores para se adaptarem às mudanças climáticas devido aos múltiplos benefícios que oferecem, dentre os quais se inclui o fornecimento de alimentos e, consequentemente, segurança alimentar, renda complementar e serviços ambientais. No caso do Brasil, a oferta de serviços ambientais relacionados à captura de carbono oferecida pelos SAF's é muito importante no sentido de reduzir a pegada ecológica do setor agrícola, um dos maiores emissores de GEE's do País.

A potencialidade de sequestro de carbono oferecido pelos SAF's pode representar incremento na renda do produtor por meio do Pagamento de Serviços Ambientais (PSA). Esse tipo de evidência foi demonstrado por Hedge e Bull (2011), que analisaram pequenos produtores que investiam em SAF's em Moçambique. Os autores concluíram que a renda e o nível de consumo das famílias que adotaram SAF's foi maior do que as não participantes (HEDGE e BULL, 2011). Resultado semelhante já havia sido evidenciado por Pagiola et al. (2008), que estudaram a adoção do sistema

Tabela 3. Impacto dos cenários climáticos sobre o valor médio da terra de municípios com e sem uso de sistemas agroflorestais, presente e simulações futuras

\begin{tabular}{|c|c|c|c|c|}
\hline \multirow{2}{*}{ Período } & \multicolumn{2}{|c|}{ Valor da Terra } & \multirow{2}{*}{ Diferença } & \multirow{2}{*}{ P-valor } \\
\hline & Com $S A F^{\prime} s$ & Sem $S A F^{\prime} S$ & & \\
\hline Presente & $160.325,4$ & $147.133,5$ & $13.191,8^{* * *}$ & 0,0000 \\
\hline 2016-2035 RCP 4.5 & $174.246,9(+8,7 \%)$ & $120.923,3(-17,8 \%)$ & $53.323,6^{* * *}$ & 0,0000 \\
\hline 2016-2035 RCP 8.5 & $171.583,0(+7,0 \%)$ & $118.181,3(-19,7 \%)$ & $53.401,7^{* * *}$ & 0,0000 \\
\hline 2046-2065 RCP 4.5 & $172.885,5(+7,8 \%)$ & $122.587,7(-16,7 \%)$ & $50.297,9^{* * *}$ & 0,0000 \\
\hline 2046-2065 RCP 8.5 & $171.569,4(+7,0 \%)$ & $122.727,6(-16,6 \%)$ & $48.841,8^{* * *}$ & 0,0000 \\
\hline
\end{tabular}

Notas: Para cada período de tempo e RCP foi considerado o valor médio de temperatura e precipitação referentes aos quatro Modelos de Circulação Geral apresentados na Metodologia; a variável ‘Valor da Terra' está cotada em 1.000 R\$ (valores referentes ao Censo Agropecuário 2006); ETM calculado pelo método Kernel; (3) P-valor baseado no erro padrão calculado por bootstrap; ${ }^{* * *}$ ) indica significância à $1 \%$.

Fonte: Resultados da pesquisa. 
silvipastoril na Nicarágua, o qual possibilitou maiores níveis de renda, além da contribuição para a recuperação de pastagens degradadas.

De modo geral, os resultados deste estudo indicam que a ampliação da adoção de SAF's poderá reduzir o risco inerente à agricultura diante os cenários futuros de mudanças climáticas. A possibilidade da diversificação produtiva decorrente do sistema tem potencial de reduzir o risco do produtor contra quebras de safras, além de novas adaptações decorrentes de veranicos mais intensos, possibilitando ainda ao produtor beneficiar-se da produção da safrinha. De modo geral, o sistema pode ajudar a manter o crescimento do agronegócio brasileiro de forma sustentável, em conformidade com os pressupostos da "agricultura inteligente face ao clima" (climate-smart agriculture).

\section{Conclusões}

Os resultados do estudo permitem concluir que a adoção de SAF's no Brasil é condicionada pelas condições agronômicas, socioeconômicas e climáticas dos municípios, com destaque para as duas últimas. Por um lado, o fato de o padrão histórico de temperatura e precipitação influenciar na escolha dessa técnica de exploração agrícola confirma sua utilização como medida adaptativa às mudanças climáticas. Por outro, a propriedade da terra e o acesso a crédito, assistência técnica e informações são fundamentais para a expansão das áreas cultivadas com SAF's no País.

É possível concluir, também, que os SAF's têm potencial de tornar a lucratividade agrícola média dos municípios (valor da terra) menos vulnerável ao clima, tanto no presente quanto em cenários futuros de mudanças climáticas. Diante dessa comprovação da importância de SAF's como medida adaptativa, deve-se disseminar as proposições da técnica, bem como os benefícios a ela associados. Torna-se ainda fundamental fornecer melhores condições para que os produtores optem por financiamentos que de fato se constituam em benefícios à sua propriedade e produ- ção. Nesse sentido, não basta apenas divulgar a existência de mecanismos de crédito, como o Plano ABC, mas informar aos agricultores a forma mais eficiente de utilizar esse financiamento em seu estabelecimento. Para isso deve contar com assistência técnica e informação sobre as práticas e benefícios que possam ser extraídos das mesmas. O produtor será então capaz de aumentar a produção agropecuária em bases sustentáveis, além de ter a possibilidade de ampliar os rendimentos provenientes de suas atividades.

De modo geral, os resultados dessa pesquisa sugerem que, dado o ainda restrito investimento em SAF's no Brasil, é urgente que a utilização desses sistemas seja incentivada. Deve-se dar condições para que haja maior investimento por unidade de área, uma vez que esse recurso adicional pode representar grande ganho de eficiência da prática. Esse "esforço adicional" visaria o oferecimento, principalmente, de assistência técnica aos produtores, de modo a dotá-los do conhecimento adequado para o uso desses sistemas. Complementarmente, a garantia dada pelo uso de SAF's no tocante à segurança alimentar pode indicar que se justificaria a concessão de algum tipo de subsídio nos casos em que a produção objetivasse o abastecimento do mercado interno. Logicamente, esses avanços somente serão obtidos num ambiente de evolução das políticas públicas e do sistema de extensão rural.

\section{Referências}

ABDO, M. T. V. N., VALERI, S. V. e MARTINS, A. L. M. Sistemas agroflorestais e agricultura familiar: uma parceria interessante. Revista Tecnologia E Inovação Agropecuária, v. 1, n. 2, 50-59, 2008.

BALBINO, L., CORDEIRO, L. e MARTÍNEZ, G. Contribuições dos sistemas de integração LavouraPecuária-Floresta (iLPF) para uma Agricultura de Baixa Emissão de Carbono. Revista Brasileira de Geografia Física, v. 4, n. 6, p. 1163-1175, 2011.

BALBINO, L. et al. Agricultura Sustentável por meio da Integração Lavoura-Pecuária-Floresta (iLPF). Informações Agronômicas, v. 138, p. 1-18, 2012. 
BECKER S. O. e ICHINO, A. Estimation of average treatment effects based on propensity score. The Stata Journal, v. 2, n. 4, p. 358-377, 2002.

BEDDINGTON, J. R. et al. What Next for Agriculture After Durban? Science, v. 335, p. 289-290, 2012.

BELOW, T. B. et al. Can farmers'adaptation to climate change be explained by socio-economic householdlevel variables? Global Environmental Change, v. 22, p. 223-235, 2012.

BRASIL. Comitê Interministerial Sobre Mudança do Clima. Plano Nacional sobre Mudança do Clima. Brasília, 2013.

BRIDI, A. M. Adaptação e Aclimatação Animal. 2000. Disponível em: <http://www.uel.br/pessoal/ambridi/ Bioclimatologia_arquivos/AdaptacaoeAclimatacao Animal.pd f > . Acesso em: mar. 2015.

CRU - Climate Research Unit, 2013. CRU/University of East Anglia. Disponível em: <https://crudata.uea.ac.uk/ cru/data/hrg/>. Acesso em: abr. 2014.

CUNHA, D. A., COELHO, A. e FÉRES, J. Irrigation as an adaptive strategy to climate change: an economic perspective on Brazilian agriculture. Environment and Development Economics, v. 20, n. 1, p. 57-79, 2015.

DOS SANTOS, L. R. et al. Factors for the adoption of agroforestry systems in the Eastern Amazon, Brazil. Revista de la Facultad de Agronomía, La Plata, v. 113, n. 2, p. 140-146, 2014.

EMBRAPA AGROBIOLOGIA. Sistemas agloflorestais (SAFs). 2004. Disponível em: <https://www.embrapa. br/busca-de-produtos-processos-e-servicos/-/produtoservico/112/sistemas-agroflorestais-safs $>$. Acesso em: jun. 2016.

FERREIRA FILHO, J. B. S. e MORAES, G. I. Climate change, agriculture and economic effects on different regions of Brazil. Environment and Development Economics, v. 20, n. 1, p. 37-56, 2015.

GARRITY, D. P. Agroforestry and the achievement of the millennium development goals. Agroforestry Systems, v. 61, n. 1, p. 5-17, 2004.

GONÇALVES, A. L. R. e VIVAN, J. L. Agroforestry and conservation projects in Brazil: carbon, biodiversity, climate, and people. 2012. Disponível em: < http:// www.fao.org/sustainable-forest-management/toolbox/ cases/case-detail/en/c/320158/> . Acesso em: jun. 2016.

HE, X., CAO, H. e LI, F. Econometric analysis of the determinants of adoption of rainwater harvesting and supplementary irrigation technology (RHSIT) in the semiarid Loess Plateau of China. Agricultural Water Management, v. 89, p. 243-250, 2007.

HEGDE, R. e BULL, G. Q. Performance of an agroforestry based Payments-for-Environmental- Services project in Mozambique: a household level analysis. Ecological Economics, v. 71, p. 122-130, 2011.

IBGE - Instituto Brasileiro de Geografia e Estatística. Censo Agropecuário 2006: Brasil, Grandes Regiões e Unidades da Federação. Rio de Janeiro: IBGE. 2006.

. Mapa do Potencial Agrícola do País. Atlas Nacional do Brasil. 4. ed. Rio de Janeiro: IBGE, 2002.

IPCC - Intergovernmental Panel On Climate Change. Climate Change 2013: The Physical Science Basis. Stocker, T; Dahe, Q; Plattner, G. K. (Eds.). Genebra, Suíça: IPCC, 2013.

. Climate Change 2014: Impacts, Adaptation, and Vulnerability. Field, C. et al. (Eds.). Genebra, Suíça: IPCC, 2014.

KASTNER, T., RIVAS, M. J. I., KOCH, W. e NONHEBEL, S. Global changes in diets and the consequences for land requirements for food. Proceedings of the National Academy of Sciences, v. 109, p. 6868-6872, 2012.

KOOHAFKAN, P., ALTIERI, A. M. e GIMENEZ, H. E. Green Agriculture: foundations for biodiverse, resilient and productive agricultural systems. International Journal of Agricultural Sustainability, v. 10, p. 61-75, 2012.

KRISHNAMOORTHY, K. e YU, J. Modified Nel and Van der Merwe test for the multivariate Behrens-Fisher problem. Statistics and Probability Letters, v. 66, n. 2, p. 161-169, 2004.

LASCO, R. et al. Climate risk adaptation by smallholder farmers: the roles of trees and agroforestry. Current Opinion in Environmental Sustainability, v. 6, p. 83-88, 2014.

LEME, T. M. S. P. et al. Comportamento de vacas mestiças Holandês x Zebu em pastagem de Brachiaria decumbens em sistema silvipastoril. Ciência Agrotécnica, v. 29, p. 668-675, 2005.

LUEDELING, E., KINDT, R., HUTH, N. I. e KOENIG, K. Agroforestry systems in a changing climate challenges in projecting future performance. Current Opinion in Environmental Sustainability, v. 6, p. 1-7, 2014.

LUNDGREN, B. O. e RAINTREE, J. B. Sustained agroforestry. In: NESTEL, B. (ed.). Agricultural Research for Development: Potentials and Challenges in Asia. ISNAR, The Hague, The Netherlands, 1982. p. 37-49. 
MACEDO, M. C. M. Integração lavora e pecuária: alternativa para sustentabilidade da produção animal. In: Simpósio Sobre Manejo Da Pastagem: Planejamento de Sistemas de Produção em Pastagem. Anais... Piracicaba: ESALQ, p. 257-283, 2001.

MAY, P. H. e VINHA, V. Adaptation to climate change in Brazil: the role of private investment. Estudos Avançados, v. 26, n. 74, p. 229-245, 2012.

MBOW, C. et al. Agroforestry solutions to address food security and climate change challenges in Africa. Current Opinion in Environmental Sustainability, v. 6, p. 61-67, 2014a.

MBOW, C. et al. Achieving mitigation and adaptation to climate change through sustainable agroforestry practices in Africa. Current Opinion in Environmental Sustainability, v. 6, p. 8-14, 2014b.

McGINTY, M. M., SWISHER, M. E. e ALAVALAPATI, J. Agroforestry adoption and maintenance: self-efficacy, attitudes and socio-economic factors. Agroforestry Systems, v. 73, n. 2, p. 99-108, 2008.

MEIJERA, S. S. et al. Nieuwenhuisb, M. The role of knowledge, attitudes and perceptions in the uptake of agricultural and agroforestry innovations among smallholder farmers in sub-Saharan Africa. International Journal of Agricultural Sustainability, v. 13, n. 1, p. 40-54, 2015a.

MEIJERA, S. S. et al. Tree planting by smallholder farmers in Malawi: using the theory of planned behaviour to examine the relationship between attitudes and behavior. Journal of Environmental Psychology, v. 43, p. 1-12, 2015b.

MELLACE, E. M. Eficiência da área de sombreamento artificial no bem estar de novilhas leiteiras criadas a pasto. 2009. 95 f. Dissertação (Mestrado) - Escola Superior de Agricultura Luiz de Queiroz, Piracicaba, SP.

MENDELSOHN, R., NORDHAUS, W. e SHAW, D. The impact of global warming on agriculture: Ricardian analysis. The American Economic Review, v. 84, n. 4, p. 753-771, 1994.

MINGOTI, S. A. Análise de dados através de métodos de estatística multivariada - uma abordagem aplicada. Belo Horizonte: Editora UFMG, 2005.

MORAES, L. F. D., RESENDE, A. S. e AMANCIO, C. O. G. Sistemas agroflorestais para o uso sustentável do solo: considerações agroecológicas e socioeconômicas. Embrapa Agrobiologia. Documentos, 281. Seropédica: Embrapa Agrobiologia, 2011. 28 p.
MOTTA, R. S. A política nacional sobre mudança do clima: aspectos regulatórios e de governança. In: MOTTA, R. S. et al. Mudança do clima no Brasil: aspectos econômicos, sociais e regulatórios. Brasília: Ipea, 2011. Cap. 1 p. 31-42.

NELSON, G. C. et al. Climate change effects on agriculture: economic responses to biophysical shocks. PNAS, v. 111, n. 9, p. 3274-3279, 2014.

OBSERVATÓRIO ABC. Propostas para revisão do Plano ABC. 2015. Disponível em: <http://www. observatorioabc.com.br/propostas-para-revisao-doplano-abc-2?locale=pt-br $>$. Acesso em: abr. 2015.

PAGIOLA, S., RIOS, A. N. e ARCENAS, A. Can the poor participate in payments for environmental services? Lessons from the Silvopastoral Project in Nicaragua. Environment and Development Economics, v. 13, n. 3, p. 299-325, 2008.

PATTANAYAK, S. K. et al. Taking stock of agroforestry adoption studies. Agroforestry Systems, v. 57, n. 3, p. 173186, 2003.

PIRES, M. F. A. et al. Physiological and behavioural parameters of crossbred heifers in single Brachiaria decumbens pasture and in silvopastoral system In: Livestock and Global Climate Change, 2008, Hammamet/Tunisia. Proceedings... Hammamet/Tunisia: EEAP, 2008. p. 115-118.

PIRES, M. V. e CUNHA, D. A. Climate Change and Adaptive Strategies in Brazil: the economic effects of genetic breeding. Revista de Economia e Sociologia Rural, v. 52, n. 4, p. 627-642, 2014.

POMPEU, G. S. S. et al. Adoption of agroforestry systems by smallholders in Brazilian Amazon. Tropical and Subtropical Agroecosystems, v. 15, n. 1, p. 165-172, 2012.

PRIMAVESI, O., ARZABE, C. e SANTOS, M. Mudanças climáticas: visão tropical integrada das causas, dos impactos e de possíveis soluções para ambientes rurais ou urbanos. São Carlos: Embrapa Pecuária Sudeste, 2007.

RINGLER, C. et al. Sustainable agricultural intensification: the promise of innovative farming practices. In: International Food Policy Research Institute (IFPRI). 2013 Global Food Policy Report. Washington, DC: 2014. p. 43-51.

ROSENBAUM, P. R. e RUBIN D. B. The Central role of the Propensity Score in observational studies for causal effects. Biometrika, v. 70, n. 1, p. 41-55, 1983. 
SCHLENKER, W., HANEMANN, W. M. e FISHER, A. C. Will U.S. agriculture really benefit from global warming? Accounting for irrigation in the hedonic approach. The American Economic Review, v. 95, n. 1, p. 395-406, 2005.

SEO, N. An analysis of public adaptation to climate change using agricultural water schemes in South America. Ecological Economics, v. 70, n. 4, p. 825-834, 2011.
WAMSLER, C., BRINK, E. e RENTALA, O. Climate Change, Adaptation, and Formal Education: The Role of Schooling for Increasing Societies' Adaptive Capacities in El Salvador and Brazil. Ecology and Society, v. 17, n. 2, p. 1-19, 2012.

YOHE, G. e TOL, R. S. J. Indicators for social and economic coping capacity - moving toward a working definition of adaptive capacity. Global Environmental Change, v. 12, n. 1, 25-40, 2002. 
Figura A1. Etapas metodológicas e estratégias empíricas utilizadas para estimação do Modelo de efeito de tratamento e Propensity Score Matching

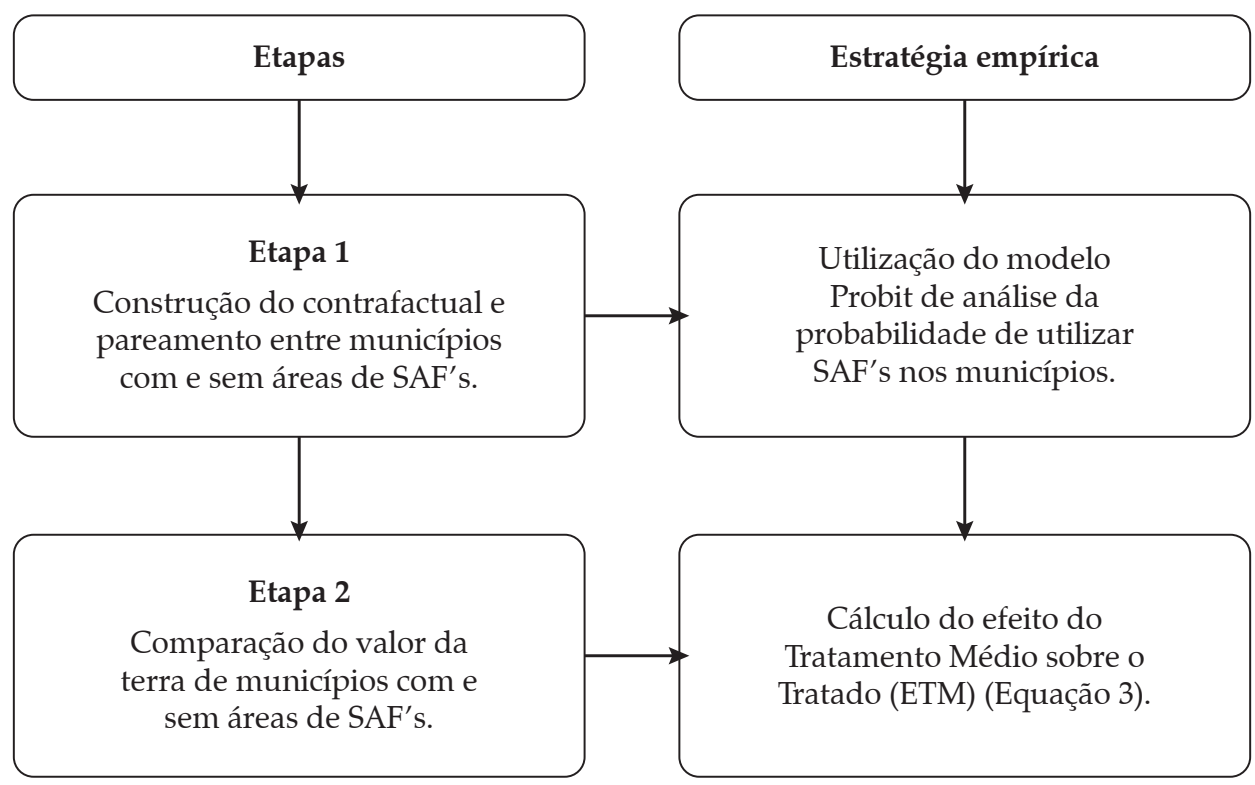

Fonte: Dados da pesquisa.

Figura A2. Etapas metodológicas e estratégias empíricas utilizadas para as simulações de mudança climática

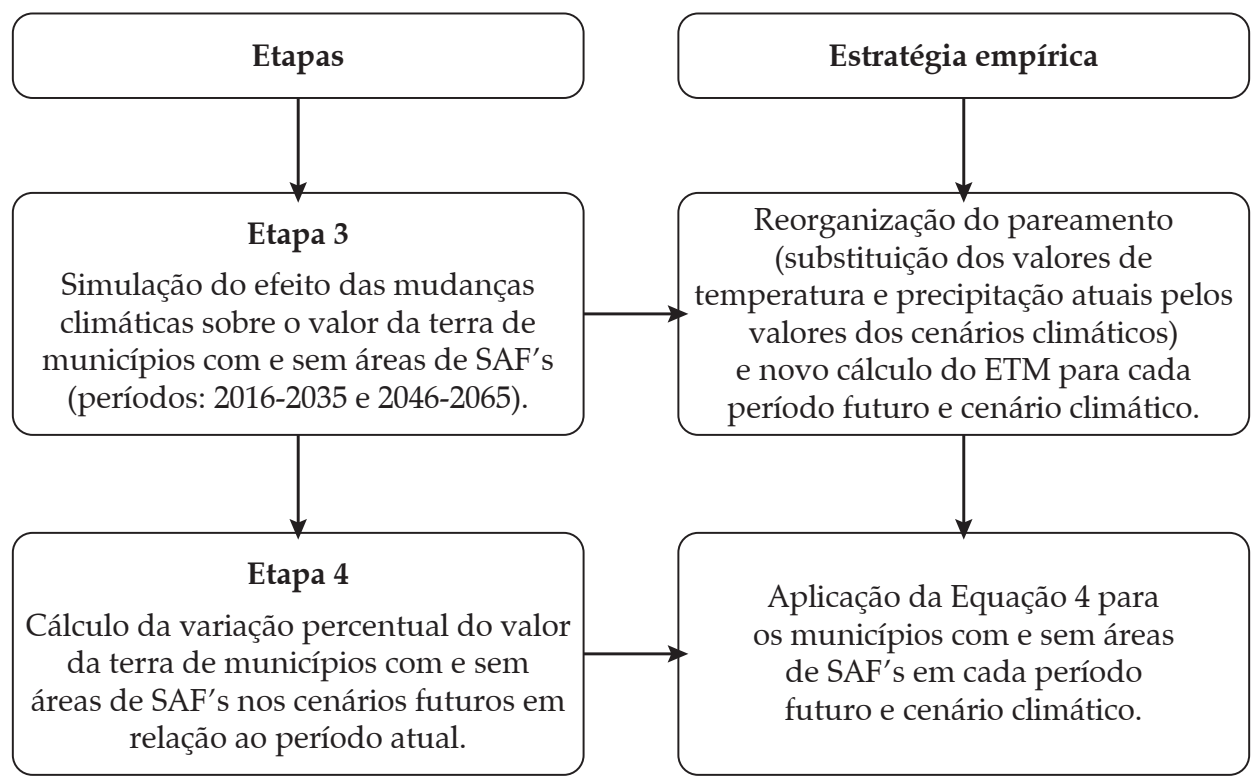

Fonte: Dados da pesquisa. 


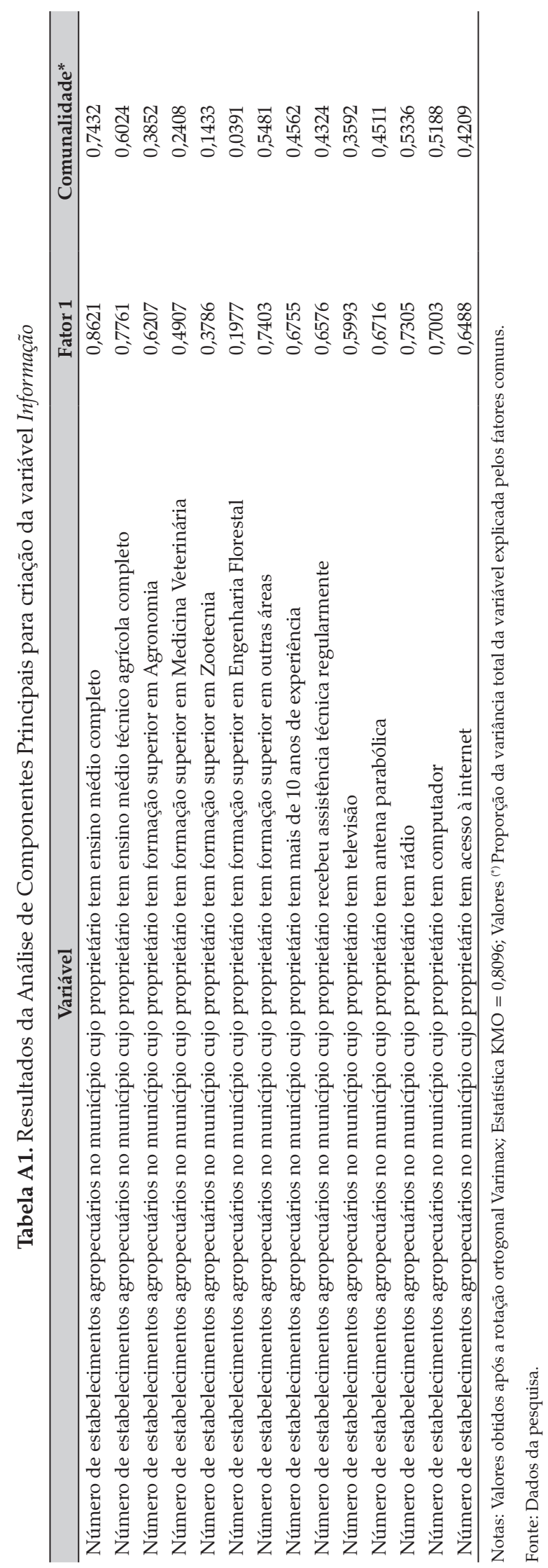

RESR, Piracicaba-SP, Vol. 55, № 01, p. 009-030, Jan./Mar. 2017 - Impressa em Junho de 2017 